\title{
HETEROGENEITY, GEOGRAPHIC DISTRIBUTION, AND PATHOGENICITY OF SERODEMES OF LEISHMANIA VIANNIA IN COLOMBIA
}

\author{
NANCY GORE SARAVIA, KRISTEN WEIGLE, CLAUDIA NAVAS, IRIS SEGURA, LILIANA VALDERRAMA, \\ ANAIS ZULLY VALENCIA, BLANCA ESCORCIA, AND DIANE MCMAHON-PRATT \\ Centro Internacional de Entrenamiento e Investigaciones Médicas, Cali, Colombia; Department of Epidemiology, University of North \\ Carolina, Chapel Hill, North Carolina; Department of Epidemiology and Public Health, Yale University School of Medicine, \\ New Haven, Connecticut
}

\begin{abstract}
Leishmania Viannia strains from 1,092 patients who acquired dermal leishmaniasis in endemic regions of Colombia were analyzed for expression of species and subgenus specific epitopes. Eight monoclonal antibodies prepared against membranes of the major species of the Viannia subgenus and previously shown to distinguish these species, recognized low molecular mass $(<45 \mathrm{kD})$ membrane components. Thirteen widely but non-uniformly distributed serodemes were identified: one unique to L. panamensis, four unique to L. braziliensis and eight that were common to $L$. braziliensis and L. guyanensis. Thirty-seven percent of Colombian L. braziliensis strains concomitantly typed by isoenzymes were null, i.e., not recognized by the corresponding species-specific B-16 or B-18 antibodies. No Colombian $L$. guyanensis strains were recognized by the antibody specific for this species (B-19). In contrast, L. panamensis-specific B-4 and B11 antibodies recognized $>98 \%$ of the L. panamensis strains. Null strains of L. braziliensis and L. panamensis were more frequently isolated from mucosal leishmaniasis than strains that expressed species specific epitopes, suggesting that these strains may be more pathogenic.
\end{abstract}

\section{INTRODUCTION}

Monoclonal antibodies have proven useful in the identification of Leishmania. ${ }^{1-5}$ Several panels of monoclonal antibodies for the identification of Leishmania isolated in different regions of the world were assembled through international collaboration and the coordination of the World Health Organization (WHO) Tropical Disease Research program. Besides application in species identification, polymorphisms in the expression of the epitopes recognized by monoclonal antibodies may have potential in discriminating epidemiologically or biologically distinct populations. Since the epitopes recognized as subgenus or species specific are surface membrane associated, ${ }^{2}$ it is conceivable that the immune response of the host could exert some selective pressure on their expression, and result in distinguishable populations.

Although the antibody panels have been widely evaluated with reference strains and a large collection of strains from Brazil, ${ }^{6-8}$ information on the reactivity of subgenus- and species-specific antibodies for Leishmania of the Viannia subgenus in the Andean region has been limited. In this report, we present the results of monoclonal antibody reactivity of more than one thousand strains of L. Viannia from patients in relation to different disease presentations and geographic distribution in Colombia. In addition, combined monoclonal antibody reactivity patterns and isoenzyme polymorphisms were used to examine intraspecies variation and the consensus between species identity based on the two phenotypic methods in 512 of these strains.

\section{MATERIALS AND METHODS}

Leishmania strains. One thousand ninety two strains of Leishmania that were isolated from the same number of patients who attended the Centro International de Entrenamiento e Investigaciones Médicas (CIDEIM) in Cali, Colombia between 1983 and 1995 for the diagnosis and treatment of dermal leishmaniasis were included in this study. Clinical histories including history or physical evidence of prior leishmaniasis and epidemiologic information on expo- sure to sand flies and acquisition of infection were obtained at the time of consultation for diagnosis. The procedures for the differential diagnosis and isolation of the parasites were previously described. ${ }^{9}$ Following isolation and initial propagation, isolates were cryopreserved and characterized using monoclonal antibodies and isoenzyme electrophoresis. ${ }^{10,11}$

The WHO reference strains for L. Viannia species were included in the characterization of patient isolates: L. panamensis (MAN/PA/1971/LS94), L. braziliensis (MAN/BR/ 1975/M2903), L. guyanensis (MAN/BR/1975/M4147), L. peruviana (MAN/PE/76/SL-5), and L. colombiensis (IHAR/CO/ 85/CL500).

Culture conditions. Promastigotes of the reference strains and strains isolated from patients were propagated in Senekjie's medium ${ }^{12}$ and/or Schneider's Drosophila medium (GIBCO-BRL, Gaithersburg, MD) supplemented with $10 \%$ heat-inactivated fetal bovine serum (FBS), 1\% glutamine, 100 $\mathrm{U} / \mathrm{ml}$ of penicillin, and $100 \mu \mathrm{g} / \mathrm{ml}$ of streptomycin (GIBCOBRL).

Cryopreservation of strains. Promastigotes were suspended in RPMI 1640 medium (GIBCO-BRL) containing 20\% heatinactivated FBS and 10\% dimethyl sulfoxide (Fischer Scientific, Pittsburgh, PA) at a concentration of $5 \times 10^{6} / \mathrm{ml}$. Vials were placed at $-70^{\circ} \mathrm{C}$ overnight, then moved to storage in liquid nitrogen. Cryopreserved material was recovered by rapid thawing and dilution in RPMI 1640 medium containing $10 \%$ heat-inactivated FBS followed by centrifugation and resuspension in appropriate medium for propagation.

Indirect immunofluorescence. Promastigotes were harvested at 3-4 days of culture by centrifugation at $1,100 \times g$ at $4^{\circ} \mathrm{C}$ for $10 \mathrm{~min}$. After the parasites were washed in phosphatebuffered saline (PBS), pH 7.2, they were counted with a hemocytometer and adjusted to a concentration of $1 \times 10^{7} / \mathrm{ml}$ in PBS. Ten-microliter aliquots containing $1 \times 10^{4}$ parasites were placed in each well of eight-well enamel-coated slides (Roboz Instrument Co., Rockville, MD). Slides were allowed to dry at room temperature, then fixed immediately with cold acetone for 10 minutes, and stored at $-20 \mathrm{C}$ until used.

Slides were blocked by incubation with PBS containing 5\% heat-inactivated fetal bovine serum for 15 minutes, then 
washed once with PBS. After drying, $10 \mu \mathrm{l}$ of monoclonal antibody as ascitic fluid diluted 1:1,000 was added to each well and the slides were incubated at room temperature for 30 minutes. The dilution of the monoclonal antibodies was based on titration against WHO reference strains for the subgenus. The panel of monoclonal antibodies used is shown in Table 1. These antibodies reactive with species pertaining to the braziliensis complex of Leishmania, now referred to as the Viannia subgenus, have been previously described. ${ }^{1,2}$ The slides were then washed three times with PBS and allowed to dry at room temperature before incubating with fluoresceinconjugated goat anti mouse $\operatorname{IgG}(10 \mu \mathrm{L} /$ well $)$ at a dilution of 1:50 (Kirkegaard and Perry Laboratories, Inc., Gaithersburg, MD). Following three washes with PBS and drying at room temperature, the slides were mounted using $90 \%$ glycerol in PBS. Fluorescence was evaluated using a Leitz Wetzlar Dialux microscope with KP490 exciter and K510 and BG38 suppression filters (E. Leitz, Rock-Leigh, NJ). Results were recorded as ++ , intense fluorescence of $100 \%$ of the promastigotes; +, well-defined fluorescence of $100 \%$ of the promastigotes; +-, weak reactivity of a variable proportion of the promastigotes; and - , no fluorescence.

Western blot analysis. Promastigote membranes were isolated using nitrogen cavitation and differential centrifugation as described ${ }^{13}$ and proteins were separated by sodium dodecyl sulfate-polyacrylamide gel electrophoresis. Proteins were transferred electrophoretically onto nitrocellulose according to the method of Towbin and others ${ }^{14}$ and processed as previously described. ${ }^{15}$

\section{RESULTS}

Western blot analyses of Leishmania (Viannia) membrane preparations using subgenus- and species-specific monoclonal antibodies. The membrane proteins recognized by the L. braziliensis- and/or L. panamensis-specific monoclonal antibodies were identified by Western blot analyses (Figure 1). The components recognized were all low molecular mass $(<45$ $\mathrm{kD}$ ). In the case of L. panamensis, some of the monoclonal antibodies appeared to recognize similar membrane components (i.e., antibodies B-4 and B-11, and B-5 and B-21). These results were consistent with known specificities of these sets of antibodies, which are specific for $L$. panamensis, and $L$.

TABLE 1

Monoclonal antibodies reactive with Leishmania

\begin{tabular}{lll}
\hline \multicolumn{1}{c}{ Specificity } & \multicolumn{1}{c}{ Hybridoma clone } & $\begin{array}{c}\text { Antibody } \\
\text { code }\end{array}$ \\
\hline L. Viannia subgenus & VI-4B9-D10 & B-2 \\
L. Viannia subgenus & XLIV-5H2-A10 & B-13 \\
L. panamensis/L. braziliensis & XIII-3H6-A12 & B-12 \\
L. panamensis/L. guyanensis & VII-6H9-G10 & B-21 \\
L. panamensis/L. braziliensis & VII-2C5-C5 & B-5 \\
L. panamensis/L. braziliensis/ & & \\
\multicolumn{1}{l}{ L. colombiensis } & VII-3E12-D3 & B-8 \\
L. panamensis & VI-2A5-A4 & B-4 \\
L. panamensis & VII-5G3-F3 & B-11 \\
L. braziliensis & XIII-3E6-B11 & B-16 \\
L. braziliensis & XIV-2A5-A10 & B-18 \\
L. guyanensis & XLIV-5A2-B9 & B-19 \\
L. donovani & LXXVIII-2E5-A8 & D-2 \\
L. mexicana/L. amazonensis & LXVIII-1D7-B8 & M-7 \\
\hline
\end{tabular}

braziliensis/L. panamensis, respectively. Notably, antibodies specific for each species (i.e., B-4 and B-11 for L. panamensis and B-16 and B-18 for L. braziliensis) did not cross-react with the other species.

Antibody reactivity profile by species and zymodeme. Serodemes were defined based upon a unique pattern of reactivity with the panel of monoclonal antibodies (Table 2). The pattern of monoclonal reactivity of $L$. panamensis strains was essentially homogeneous. All but six of 906 strains of L. panamensis isolated from patients, as well as the WHO reference strain for the species MHOM/PA/71/LS94, reacted with species-specific monoclonal antibodies B4 and B11 and subgenus-reactive antibodies B2 and B21 by indirect immunofluorescence, (Serodeme 1) (Table 2). Five of the six L. panamensis strains that failed to react with the species-specific antibodies reacted with at least one subgenus-specific antibody. Most of the limited heterogeneity in monoclonal antibody reactivity of this species was found in a single zymodeme (2.3) (Table 3).

In contrast with L. panamensis, the Colombian L. braziliensis strains displayed nine different reactivity profiles or serodemes using the monoclonal antibody panel. Four of these, 2a, b, c, and d (Table 2) were unique to L. braziliensis strains; 2 a was predominant. Eight serodemes were observed within a single L. braziliensis zymodeme (1.1) (Table 3). Thirty-seven (41\%) of 91 L. braziliensis strains also typed by isoenzymes showed the same pattern of reactivity as the WHO reference strain for L. braziliensis (MHOM/BR/75/M2903) and were reactive with the species specific-antibodies B16 and B18 (Serodeme 2a) (Table 3). Thirty-four (37\%) of the Colombian $L$. braziliensis strains classified in four of seven zymodemes failed to react with these species-specific antibodies.

Colombian strains of L. guyanensis were not reactive with the species-specific antibody B19 under the indirect flourescent antibody test conditions used. Three reactivity profiles with the monoclonal antibody panel were observed for this species: serodemes 3a, 3b, and 8. Most strains of L. guyanensis belonged to serodeme $3 \mathrm{~b}$, which was defined by reactivity with antibodies B2 and B12. Reactivity with monoclonal antibody B21 was infrequent. As observed for the other species of the Viannia subgenus, no serodeme of L. guyanensis was restricted to any particular zymodeme.

None of the 1,092 strains belonging to the Viannia subgenus reacted with monoclonal antibodies that recognize $L$. donovani (D2), or L. mexicana/L. amazonensis (M-7), confirming the specificity of the latter antibodies.

Geographic distribution of serodemes. Serodemes $1(L$. panamensis) and 2a (L. braziliensis) were prevalent throughout the hydrographic regions of Colombia (Figure 2 and Table 4). The Pacific coast region (constituted by the Atrato, San Juan, Patía, and Mira River basins), which is the predominant source of cases that attend the CIDEIM, yielded strains of L. Viannia having 11 different reactivity profiles with the panel of monoclonal antibodies. All but three of these, serodemes 2c, 5, and 9, have been found among strains from other hydrographic regions. Ten serodemes were identified among strains from the Amazon river basin and two of these, $2 \mathrm{~d}$ and 8 , were only observed among strains from this hydrographic region.

The distribution of strains that were non-reactive with species-specific monoclonal antibodies was not uniform. Seventy-four percent (42 of 57) of the strains originating in the 

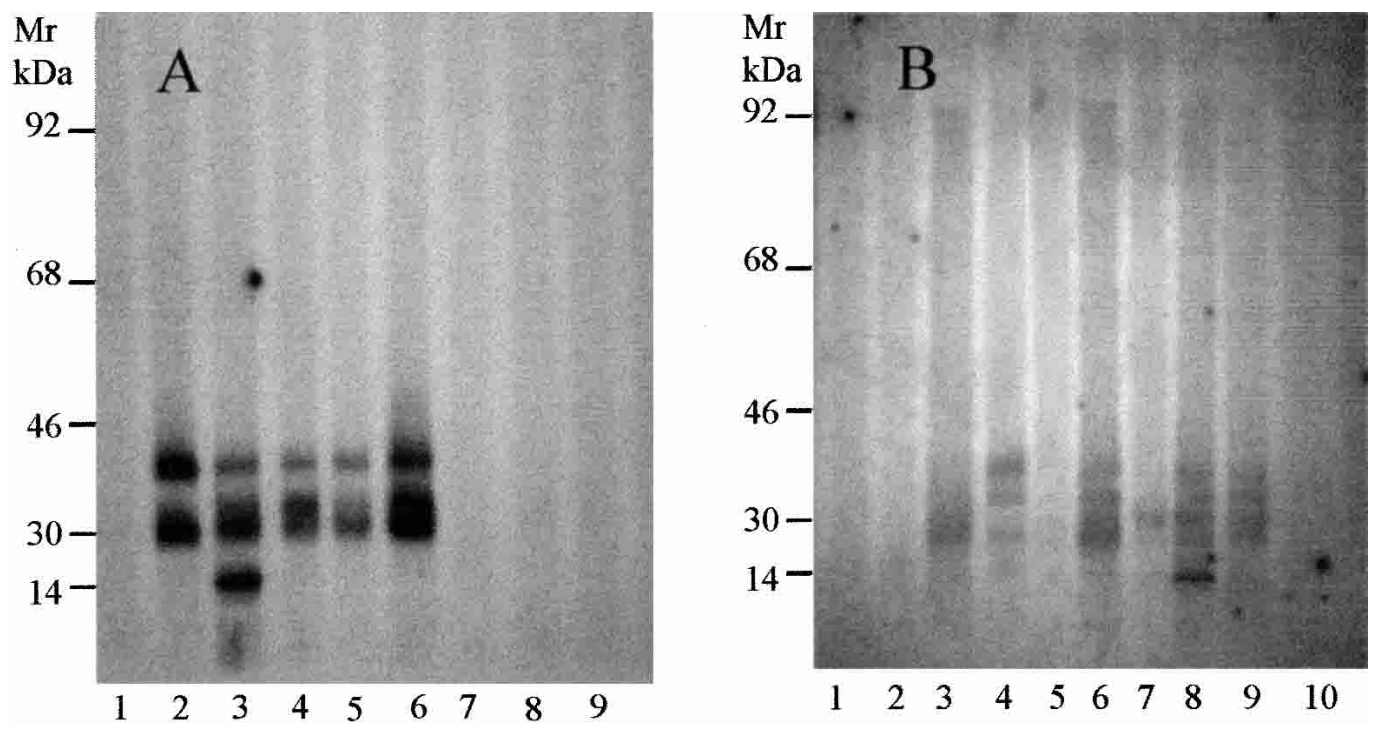

Figure 1. Western blot analyses of membrane preparations of $\mathbf{A}$, Leishmania panamensis and $\mathbf{B}$, L. braziliensis promastigotes using monoclonal antibodies. Lane 1, M-7 (LXVII-ID7-B8; negative control); lane 2, B-4 (VI-2A5-A4); lane 3, B-2 (VI-4B9-D10); lane 4, B-5 (VII-2C5-C5); lane 5, B-11 (VI-5G3-F3); lane 6, B-21 (VII-6H9-G10); lane 7, B-16 (XII-3E6-B11); lane 8, B-12 (XIII-3H6-A12); lane 9, B-18 (XIV-2A5-A10); lane 10, B-19 (XLIV-5A2-B9). Values on the right of each blot are molecular mass $\left(\mathrm{M}_{\mathrm{r}}\right)$ values in kilodaltons $(\mathrm{kDa})$.

Amazon River basin were non-reactive with species-specific monoclonal antibodies, whereas in the two other hydrographic regions from which a substantial number of strains had originated (Atrato and San Juan, and Patía and Mira River basins) only $5.2 \%$ of 267 and $4.5 \%$ of 726 strains, respectively, were non-reactive (Table 4). Leishmania guyanensis constituted approximately $75 \%$ of the non-reactive strains from the Amazon River basin and L. braziliensis 25\%, while L. braziliensis predominated among the non-reactive strains from the river basins of the Pacific coast region.

Colombian strains compared with $L$. Viannia species from neighboring countries. The strains of $L$. peruviana and $L$. bra- ziliensis from Peru that were examined were found to react with L. braziliensis-specific antibodies B16 and B18, as well as subgenus-specific antibodies B12 and B2, a pattern corresponding with Colombian serodeme 2a. However, as found among many Colombian strains, reactivity with B16 was weak for some strains of $L$. braziliensis from Peru. The Peruvian strains of $L$. braziliensis and L. peruviana varied in their reactivity with antibody B21. Reference strains for L. colombiensis and L. ecuatorensis did not react in the indirect IFAT assay using this panel of monoclonal antibodies for Leishmania Viannia. The profiles of isoenzyme polymorphisms of these two species were distinct from those of the more than

TABLE 2

Reactivity of Colombian Leishmania Viannia with subgenus- and species-specific monoclonal antibodies*

\begin{tabular}{|c|c|c|c|c|c|c|c|c|c|c|}
\hline \multirow{2}{*}{\multicolumn{2}{|c|}{$\begin{array}{c}\text { Specificity } \dagger \\
\text { antibody designation }\end{array}$}} & \multicolumn{8}{|c|}{ Reactivity with monoclonal antibodies } & \multirow[b]{2}{*}{$\begin{array}{c}\text { Total } \\
\text { strains }\end{array}$} \\
\hline & & $\begin{array}{l}\text { Lp } \\
\text { B11 }\end{array}$ & $\begin{array}{l}\text { Lb } \\
\text { B16 }\end{array}$ & $\begin{array}{l}\text { Lb } \\
\text { B18 }\end{array}$ & $\begin{array}{c}\mathrm{Lg} \\
\mathrm{B} 19\end{array}$ & $\begin{array}{l}\text { LV } \\
\text { B2 }\end{array}$ & $\begin{array}{l}\mathrm{Lp} / \mathrm{Lb} \\
\mathrm{B} 21\end{array}$ & $\begin{array}{c}\mathrm{Lb} / \mathrm{Lg} \\
\mathrm{B} 12\end{array}$ & $\underset{\mathrm{B} 4}{\mathrm{Lp} / \mathrm{Lb}}$ & \\
\hline \multicolumn{11}{|c|}{ Reference strains $L$. Viannia } \\
\hline LS 9 & 4 (L.V. panamensis) & ++ & - & - & - & ++ & ++ & - & ++ & - \\
\hline M41 & 47 (L. V. guyanensis) & - & - & - & + & + & - & ++ & - & - \\
\hline M29 & 03 (L.V. braziliensis) & - & ++ & ++ & - & ++ & ++ & ++ & - & - \\
\hline \multicolumn{11}{|c|}{ Colombian serodeme } \\
\hline 1 & & ++ & - & - & - & ++ & ++ & - & ++ & 900 \\
\hline \multirow[t]{4}{*}{2} & $\mathrm{a}$ & - & ++ & ++ & - & ++ & ++ & ++ & - & 82 \\
\hline & $\mathrm{b}$ & - & - & + & - & ++ & ++ & ++ & - & 9 \\
\hline & $\mathrm{c}$ & - & - & + & - & ++ & ++ & - & - & 5 \\
\hline & $\mathrm{d}$ & - & - & + & - & ++ & - & ++ & - & 1 \\
\hline \multirow[t]{2}{*}{3} & $\mathrm{a}$ & - & - & - & - & ++ & ++ & ++ & - & 25 \\
\hline & $\mathrm{b}$ & - & - & - & - & ++ & - & ++ & - & 32 \\
\hline 4 & & - & - & - & - & - & - & + & - & 6 \\
\hline 5 & & - & - & - & - & $+1-$ & + & $+1-$ & $+1-$ & 7 \\
\hline 6 & & - & - & - & - & - & + & + & - & 11 \\
\hline 7 & & - & - & - & - & - & - & - & - & 10 \\
\hline 8 & & - & - & & - & + & - & - & - & 2 \\
\hline 9 & & - & - & - & - & + & + & - & - & 2 \\
\hline Total & & & & & & & & & & 1,092 \\
\hline
\end{tabular}

$*++=$ intense fluorescence $(100 \%) ;+=$ well-defined fluorescence; $+/-=$ weak fluorescence variable $\% ;-=$ no fluorescence

$\dagger \mathrm{Lp}=$ L. panamensis; $\mathrm{Lb}=$ L. braziliensis; $\mathrm{Lg}=$ L. guyanensis; $\mathrm{LV}=$ L. Viannia subgenus. 
TABLE 3

Serodemes identified among Colombian Leishmania Viannia species and zymodemes using a monoclonal antibody panel for the Viannia subgenus

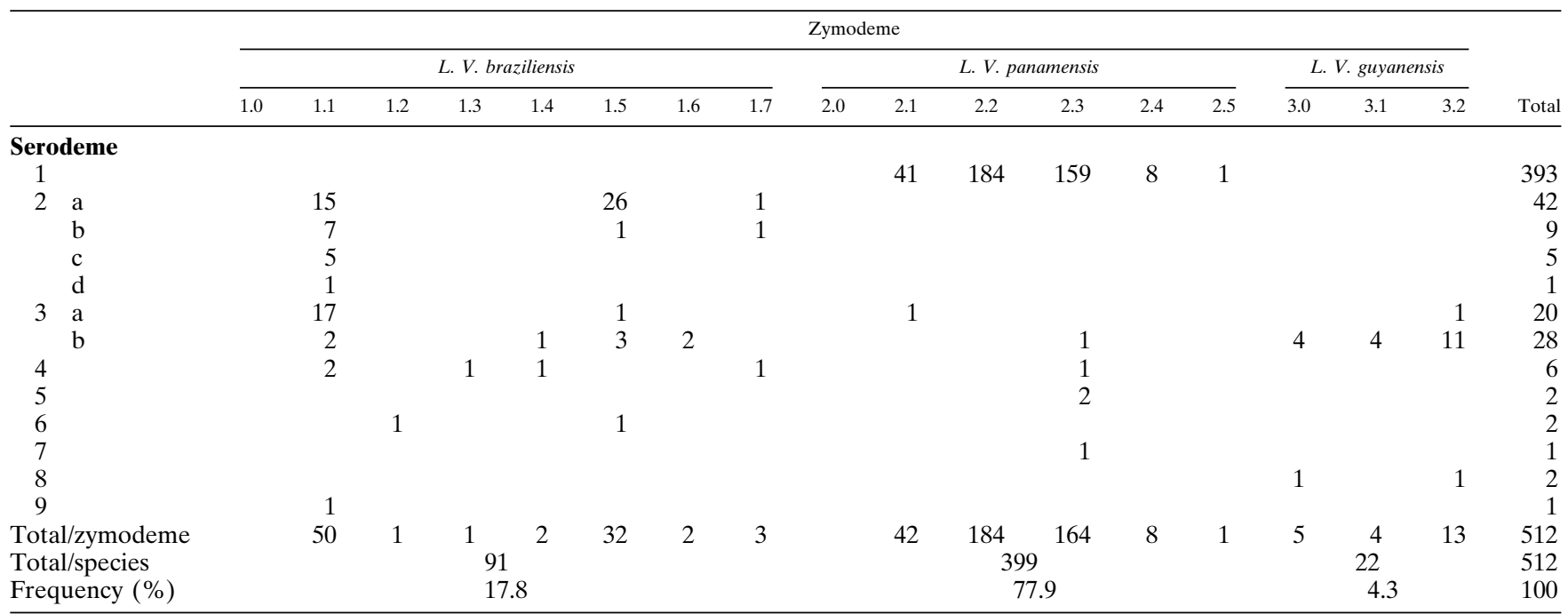

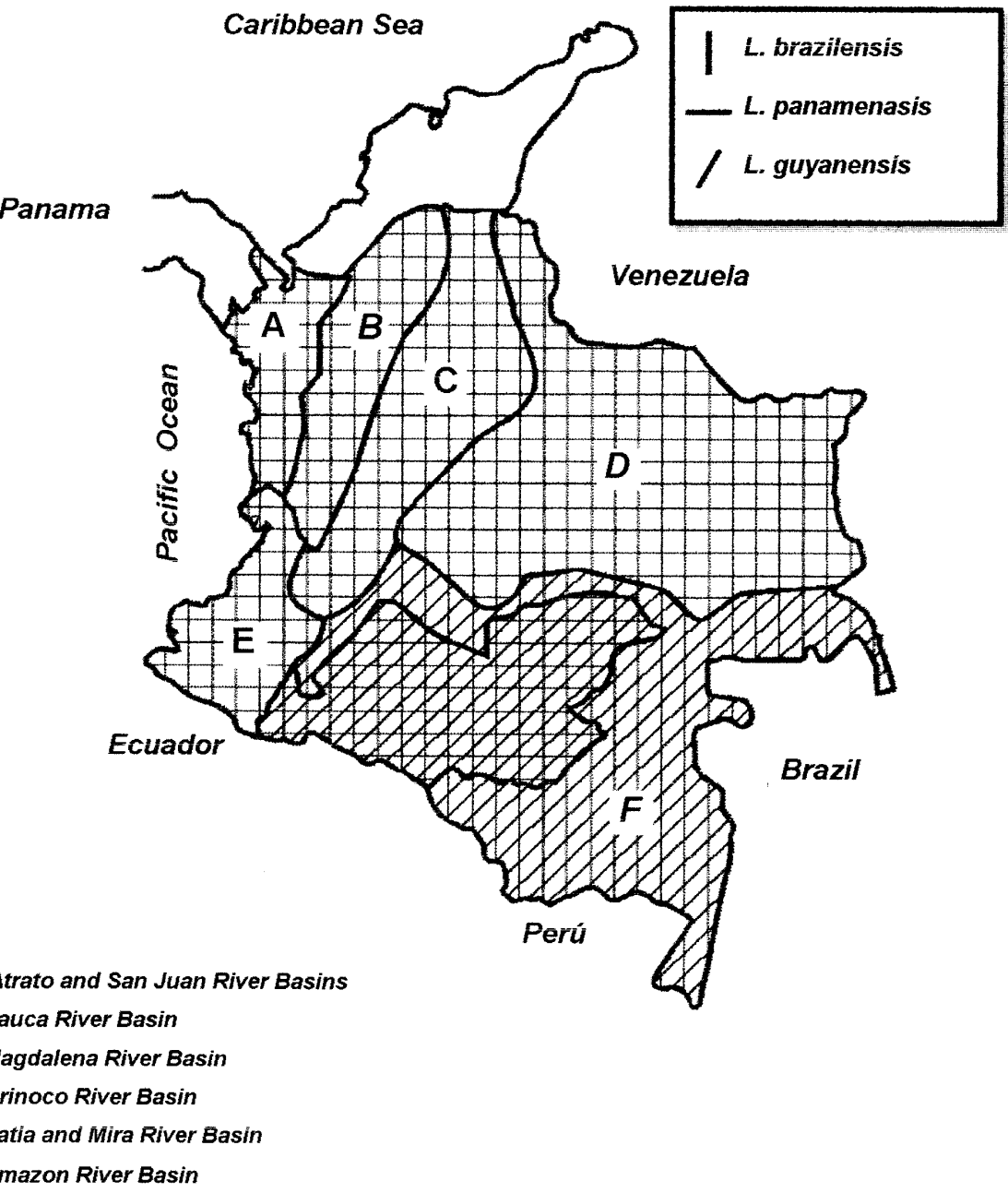

FIGURE 2. Map of hydrographic regions of Colombia showing the Leishmania Viannia species distribution based on monoclonal antibody typing. Leishmania panamensis has been identified among isolates from patients reporting acquisition of infection in the states of Putumayo, Caqueta and Guaviare within the Amazon River Basin. 
TABLE 4

Geographic distribution of Colombian serodemes of Leishmania Viannia

\begin{tabular}{|c|c|c|c|c|c|c|c|c|c|}
\hline & \multirow[b]{2}{*}{ Serodeme } & \multicolumn{8}{|c|}{ Hydrographic regions } \\
\hline & & $\begin{array}{c}\text { Atrato and } \\
\text { San Juan } \\
\text { River Basin }\end{array}$ & $\begin{array}{l}\text { Patia and } \\
\text { Mira } \\
\text { River Basin }\end{array}$ & $\begin{array}{l}\text { Cauca } \\
\text { River } \\
\text { Basin }\end{array}$ & $\begin{array}{l}\text { Magdalena } \\
\text { River } \\
\text { Basin }\end{array}$ & $\begin{array}{l}\text { Orinoco } \\
\text { River } \\
\text { Basin }\end{array}$ & $\begin{array}{l}\text { Amazon } \\
\text { River } \\
\text { Basin }\end{array}$ & $\begin{array}{c}\text { Atlantic } \\
\text { Coast }\end{array}$ & Total \\
\hline & 1 & 187 & 672 & 11 & 12 & 4 & 10 & 4 & 900 \\
\hline Species-specific & a & 66 & 8 & 1 & 3 & & 3 & 1 & 82 \\
\hline serodemes & $2 \mathrm{~b}$ & & 8 & & & & 1 & & 9 \\
\hline & $\mathrm{c}$ & & 5 & & & & & & 5 \\
\hline & $\mathrm{d}$ & & & & & & 1 & & 1 \\
\hline & Subtotal by region & 253 & 693 & 12 & 15 & 4 & 15 & 5 & 997 \\
\hline & $\%$ Reactive by region & 94.8 & 95.5 & 92.3 & 88.2 & 57.1 & 22.8 & 100.0 & 91.3 \\
\hline & $3 \mathrm{a}$ & 4 & 16 & & 1 & 1 & 3 & & 25 \\
\hline & $\mathrm{b}$ & 1 & 3 & 1 & 1 & 1 & 25 & & 32 \\
\hline & 4 & & 2 & & & 1 & 3 & & 6 \\
\hline Null & 5 & 3 & 4 & & & & & & 7 \\
\hline serodemes & 6 & 3 & 5 & & & & 3 & & 11 \\
\hline & 7 & 3 & 1 & & & & 6 & & 10 \\
\hline & 8 & & & & & & 2 & & 2 \\
\hline & 9 & & 2 & & & & & & 2 \\
\hline & Subtotal by region & 14 & 33 & 1 & 2 & 3 & 42 & 0 & 95 \\
\hline & $\%$ Null by region & 5.2 & 4.5 & 7.7 & 11.8 & 42.9 & 73.7 & $\mathbf{0}$ & 8.7 \\
\hline Total & & 267 & 726 & 13 & 17 & 7 & 57 & 5 & 1092 \\
\hline Frequency (\%) & & 24.4 & 66.5 & 1.2 & 1.6 & 0.6 & 5.2 & 0.5 & 100.0 \\
\hline
\end{tabular}

500 strains of L. panamensis, L. guyanensis, and L. braziliensis evaluated by both typing methods.

Relationship between antibody reactivity and clinical outcome of infection. The frequency of mucosal disease was higher among L. braziliensis and L. panamensis strains that were non-reactive with species-specific monoclonal antibodies than among strains that expressed these epitopes (Figure 3 ). This association of a null phenotype with mucosal disease was observed for both $L$. panamensis and L. braziliensis, although it was statistically significant only for L. panamensis $(P=0.029)$. Cutaneous and mucosal isolates (seven pairs) from the same patients were not distinguishable with respect to monoclonal antibody reactivity profile. Lymphadenopathy, time of evolution, recurrent lesions, and size or number of lesions were not correlated with Leishmania phenotype based on reactivity with this monoclonal antibody panel.

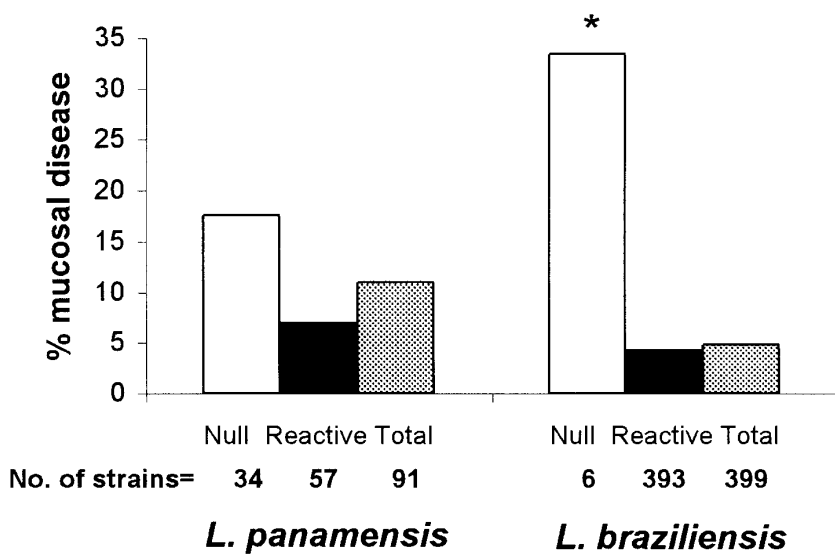

Figure 3. Frequency of mucosal disease in relation to reactivity of Colombian strains of Leishmania braziliensis and L. panamensis with species-specific monoclonal antibodies for L. braziliensis (B-16 and/or B-18) and L. panamensis (B-11). ${ }^{*} P=0.029$, by Fisher's test.

\section{DISCUSSION}

Conservation of the reactivity profile including speciesspecific B4 and B11 antibodies among strains of L. panamensis from a wide geographic range contrasts with the high variability of the pattern of monoclonal antibody reactivity of $L$. braziliensis. The marked disparity in heterogeneity of these two species was also evident as isoenzyme polymorphisms, ${ }^{11}$ and is even more striking in the expression of membrane antigen determinants recognized by monoclonal antibodies. Grimaldi and others ${ }^{6}$ initially found the reactivity of $L$. braziliensis strains to the species-specific B16 and B18 antibodies to be conserved among strains examined from Brazil, Venezuela, and Central America, but not among the strains examined from Peru. Subsequent analyses of Leishmania isolates from the Amazon region of Brazil revealed variable reactivity of some strains of $L$. braziliensis with the B16 antibody and L. guyanensis strains that did not react with the species-specific B19 antibody. ${ }^{8}$ Since the type strain used to produce the L. braziliensis-specific antibodies is a reference strain originating in Brazil, the divergence of epitope expression among strains from the Andean region could result from geographic isolation of some populations of L. braziliensis. However, geographic isolation does not seem to explain the distribution of $L$. braziliensis strains that do not react with species-specific antibodies since Colombian Leishmania lacking the species-specific epitopes or null phenotype originated from the Amazon River basin as well as the Pacific coast, i.e., regions separated by three ranges of the Andes mountains. On the other hand, human migrations could in effect reduce or eliminate the isolation imposed by geographic barriers to the dispersal of vector populations and sylvatic mammalian reservoirs. Also, because the frequency of non-reactivity with species-specific antibodies differed among the species of L. Viannia, the prevalence of different species in different regions clearly influenced the overall proportion of null strains. 
The diversity of (10) and predominance of null phenotypes among the 57 strains of L. Viannia from the southwestern departments of Colombia within the Amazon River basin (Putumayo, Caquetá, and Guaviari) is noteworthy. This region also presented the highest diversity of zymodemes of $L$. braziliensis (5) and L. guyanensis (4) compared with all other hydrographic regions of Colombia. ${ }^{11}$ Similarly, 15 L. braziliensis strains from the Brazilian Amazon were found to be highly polymorphic, constituting seven zymodemes and five serodemes. ${ }^{8}$ Genetic divergence of Lutzomyia shannoni populations present in the Amazon basin from other populations of this zoophilic species has recently been reported. ${ }^{16}$ Although the role of this sand fly species, the most widespread in the Americas, in the transmission of Leishmania of the Viannia subgenus is unknown, genetic divergence of a vector species could be expected to be accompanied by genetic differences in the parasites that they transmit.

Up until 1990 no one had previously identified L. panamensis among isolates from individuals who reported acquiring infection in the Amazon river basin. ${ }^{11,17}$ In this study, a cluster of 10 strains, nine isolated from soldiers and one from a farmer who reported acquisition of infection between 1990 and 1993 in diverse sites in the states of Putumayo and Caquetá, were identified as L. panamensis. Considering the mobility and repeated exposure of military personnel to different endemic foci, we cannot be certain whether the infections may have been acquired elsewhere, were introduced by movements of human populations, ${ }^{8,18}$ or indicate an endemic focus of L. panamensis in a region where L. braziliensis and L. guyanensis predominate. Thus, the influence of geographic isolation on genotypic and phenotypic markers may be more difficult to discern in settings characterized by intense human migratory activity as has occurred in Colombia during the last decade.

The possibility that strains of $L$. Viannia that did not react with species-specific antibodies were $L$. colombiensis or $L$. ecuatorensis was ruled out by the unique isoenzyme profiles of the latter species. The non-reactivity of the reference strains in this analysis using the IFAT with antibodies B4, B8, or B13 contrasts with findings reported using a radioimmunoassay (RIA) in the original description of these species. ${ }^{19,20}$ This discrepancy could be due either to the lower sensitivity of the IFAT or differences in access to the epitopes in membrane preparations used in RIA compared with intact promastigotes used in the IFAT.

The enzymes evaluated for polymorphisms detectable as charge isoforms are constitutive gene products, whereas the antigen determinants detected by monoclonal antibodies, which are variably expressed, evidently are not constitutive. Non-essential gene products could be expected to show greater variability since mutations or epigenetic changes could accumulate without lethal consequences, and would be conserved if they provided some selective advantage. Therefore, the conserved expression of cell membrane antigen determinants that distinguish L. panamensis from other species of Leishmania is noteworthy. Conversely, the conservation of serologically recognized determinants in strains isolated from the same patient after relapse of disease or metastasis from cutaneous to mucosal sites suggests that the host immune response does not alter the expression of these determinants. This could be explained by the fact that these antigens are expressed on the promastigote stage, and the host is predominantly exposed to the amastigote stage.

Alternatively, the association of mucosal disease with strains that lacked species-specific epitopes (null strains) raises the possibility that these strains are more likely to metastasize and colonize mucosal tissue. Examination of several null mucosal strains by RIA corroborated the absence of the corresponding epitopes. ${ }^{10}$ The heterogeneous reactivity of a secondary panel of eight monoclonal antibodies prepared against one of the null strains of L. braziliensis (Man/CO/84/ L-87), when used to examine B16/B18 positive and null strains of the same species, did not identify an epitope unique to null strains, or common to L. braziliensis strains that either lacked or expressed the species-specific epitopes. Conceivably, the absence of epitopes common to most strains of a species could influence the host response and thus the outcome of infection. The phenotypic differences may be markers of biologic differences or could themselves be functionally involved in the biology of the host-parasite relationship. The present results suggest an association between the lack of these epitopes and mucosal disease and, allow and the formulation of the hypothesis that null strains may be more pathogenic. Experimental studies are required to address this hypothesis.

The determinants recognized by monoclonal antibodies B-4, B-11 and B-16, B-18 appear to be completely specific for L. panamensis and L. braziliensis, respectively. This is in contrast to certain other species-specific determinants of L. donovani, the L. mexicana complex and L. major, ${ }^{3-5}$ which are not exposed on immunofluorescence or radioimmune binding assays using either whole organisms or isolated membrane preparations, but become accessible upon solubilization with detergent. However, given the similar molecular masses of the molecules associated with the determinants recognized by B-21 (L. panamensis/L. braziliensis specific) and B-18 (L. braziliensis-specific) it is not clear whether these epitopes might be associated with the same molecules. The general conservation of these epitopes in the respective species and their apparent association on similar molecules suggest that these molecules may have an important biologic function. Nevertheless, further work is needed to clarify the molecular relationship among these epitopes and their biologic significance.

The use of monoclonal antibodies for typing by IFAT is simple and efficient for strains that are reactive with the species-defining antibodies. In the Andean region, it can be anticipated that a proportion of L. guyanensis and L. braziliensis strains will not be identified to the species level with the existing panel and additional methods such as the polymerase chain reaction $^{21}$ or isoenzymes will be needed to establish species identity. Notwithstanding this qualification, the panel of monoclonal antibodies is highly useful for identifying the majority of isolates, and in areas of South America where some strains do not react with species-specific monoclonal antibodies, this tool provides an efficient first screening method.

Acknowledgments: We thank the clinical staff of CIDEIM; Drs. Fernando Martinez, Miguel Escobar, and Carlos Rojas; Aura Garcia and Wilson Cortez; and personnel of the Regional Hospital San Andres in Tumaco for their assistance in the clinical assessment and management of the patients who participated in this study. 
Financial support: This work was supported in part by grants 3-P-820090 and 3-P-85-0279 IDRC of Canada, grant ID $840336 \mathrm{WHO} /$ UNDP/World Bank Special Program for Tropical Disease Research; USNIAID grant P50-AI-30603, and COLCIENCIAS grants 222905001-87 and 229-04-002-92.

Authors' addresses: Nancy Gore Saravia, Claudia Navas, Iris Segura, Liliana Valderrama, Anais Zully Valencia, and Blanca Escorcia, Centro Internacional de Entrenamiento e Investigaciones Médicas, Apartado Aéreo 5390, Cali, Colombia, Telephone: 57-2-668-2164, Fax: 57-2-667-2989, E-mail: cideim@cideim.org.co. Kristen Weigle, Department of Epidemiology, University of North Carolina, School of Public Health, Chapel Hill, NC, Telephone: 919-966-7439, Fax: 919966-2089. Diane McMahon-Pratt, Yale University Research Unit, Department of Epidemiology and Public Health, Yale University School of Medicine, New Haven, CT 06510-8034, Telephone: 203785-4481, Fax: 203-737-2921, e-mail: dmm22@e-mail.med.yale.edu.

Reprint requests: Nancy Gore Saravia, Centro Internacional de Entrenamiento e Investigaciones Médicas, Apartado Aéreo 5390, Cali, Colombia, E-mail: saravia@cideim.org.co.

\section{REFERENCES}

1. McMahon-Pratt D, David JR, 1981. Monoclonal antibodies that distinguish between New World species of Leishmania. Nature 291: 581-583.

2. McMahon-Pratt D, Bennett E, David JR, 1982. Monoclonal antibodies that distinguish subspecies of Leishmania braziliensis. J Immunol 129: 926-927.

3. Jaffe CL, McMahon-Pratt D, 1983. Monoclonal antibodies specific for Leishmania tropical. I. Characterization of antigens associated with stage and species-specific determinants. J Immunol 131: 1987-1993.

4. Jaffe CL, Bennett E, Grimaldi G Jr, McMahon-Pratt D, 1984. Production and characterization of species-specific monoclonal antibodies against Leishmania donovani for immunodiagnosis. J Immunol 133: 440-447.

5. McMahon-Pratt D, Bennett E, Grimaldi G, Jaffe CL, 1985. Subspecies and species-specific antigens of Leishmania mexicana characterized by monoclonal antibodies. J Immunol 134: 19351940.

6. Grimaldi G Jr, David JR, McMahon-Pratt D, 1987. Identification and Distribution of New World Leishmania species characterized by serodeme analysis using monoclonal antibodies. Am J Trop Med Hyg 36: 270-287.

7. McMahon-Pratt D, Jaffe CL, Bennett E, David JR, Grimaldi G $\mathrm{Jr}$, 1986. Studies employing monoclonal antibodies for the analysis of the genus Leishmania Ross, 1903. Leishmania. Taxonomie et Phylogenese. Applications Eco-épidemiologiques. Montpellier, France: IMEEE, 173-178.

8. Grimaldi G Jr, Momen H, Naiff RD, McMahon-Pratt D, 1991. Characterization and classification of leishmanial parasites from humans, wild mammals, and sand flies in the Amazon region of Brazil. Am J Trop Med Hyg 44: 645-661.
9. Weigle KA, Davalos M, Heredia P, Molineros R, Saravia NG, D'Alessandro A, 1987. Diagnosis of cutaneous and mucocutaneous leishmaniasis in Colombia: a comparison of seven methods. Am J Trop Med Hyg 36: 489-496.

10. Saravia NG, Holguin AF, McMahon-Pratt D, D'Alessandro A, 1985. Mucocutaneous leishmaniasis in Colombia: Leishmania braziliensis subspecies diversity. Am J Trop Med Hyg 42: 206214.

11. Saravia NG, Segura I, Holguin AF, Santrich C, Valderrama L, Ocampo C, 1998. Epidemiologic, genetic, and clinical associations among phenotypically distinct populations of Leishmania (Viannia) in Colombia. Am J Trop Med Hyg 59: 86-94.

12. Senekjie HA, 1939. Studies on the culture of Leishmania tropica. Trans $R$ Soc Trop Med Hyg 33: 267-269.

13. Pan AA, McMahon Pratt D, 1988. Monoclonal antibodies specific for the amastigote stage of Leishmania pifanoi. I. Characterization pf antigens associated with stage and species specific determinants. J Immunol 140: 2406-2414.

14. Towbin H, Staehelin T, Gordon J, 1979. Electrophoretic transfer of proteins from polyacrylamide gels to nitrocellulose sheets: procedure and some applications. Proc Natl Acad Sci USA 76: 4350-4354.

15. Eperon S, McMahon-Pratt D, 1989. Extracellular amastigote forms of Leishmania panamensis and L. braziliensis. II Stage and species specific monoclonal antibodies. J Protozool 36: $510-518$.

16. Mukhopadhyay J, Ghosh K, Ferro C, Munstermann LE, 2001. Distribution of Phlebotamine sand fly genotypes (Lutzomyia shannoni, Diptera: Psychodidae) across a highly heterogeneous landscape. J Med Entomol 38: 260-267.

17. Corredor A, Kreutzer RD, Tesh R, Boshell J, Palau MT, Cáceres E, Duque S, Pelaez D, Rodríguez G, Nichols S, Hernández CA, Morales A, Young DG, Ferro de Carrasquilla C, 1990. Distribution and etiology of leishmaniasis in Colombia. Am J Trop Med Hyg 42: 206-215.

18. Montoya J, Jaramillo C, Palma G, Gomez T, Segura I, Travi B, 1990. Report of an epidemic outbreak of tegumentary leishmaniasis in a coffee-growing area of Colombia. Mem Inst Oswaldo Cruz 85: 119-121.

19. Grimaldi G, Kreutzer RD, Hashiguchi Y, Gomez EA, Mimory T, Tesh RB, 1992. Description of Leishmania equatorensis SP.N (Kinetoplastida: Trypanosomatidae), A new parasite infecting arboreal mammals in Ecuador. Mem Inst Oswaldo Cruz 87: 221-228.

20. Kreutzer RD, Corredor A, Grimaldi G Jr, Grogle M, Rowton ED, Young D, Morales A, McMahon-Pratt D, Guzman H, Tesh RB, 1991. Characterization of Leishmania colombiensis SP.N (Kinetoplastida:Trypanosomatidae), A new parasite infecting humans, animals and phlebotomine sand flies in Colombia and Panama. Am J Trop Med Hyg 44: 662-675.

21. Rodriguez NB, Guzmán A, Rodas H, Takiff H, Bloom BR, Convit J, 1994. Diagnosis of cutaneous leishmaniasis and species discrimination of parasites by PCR and hybridization. J Clin Microbiol 32: 2246-2252. 